
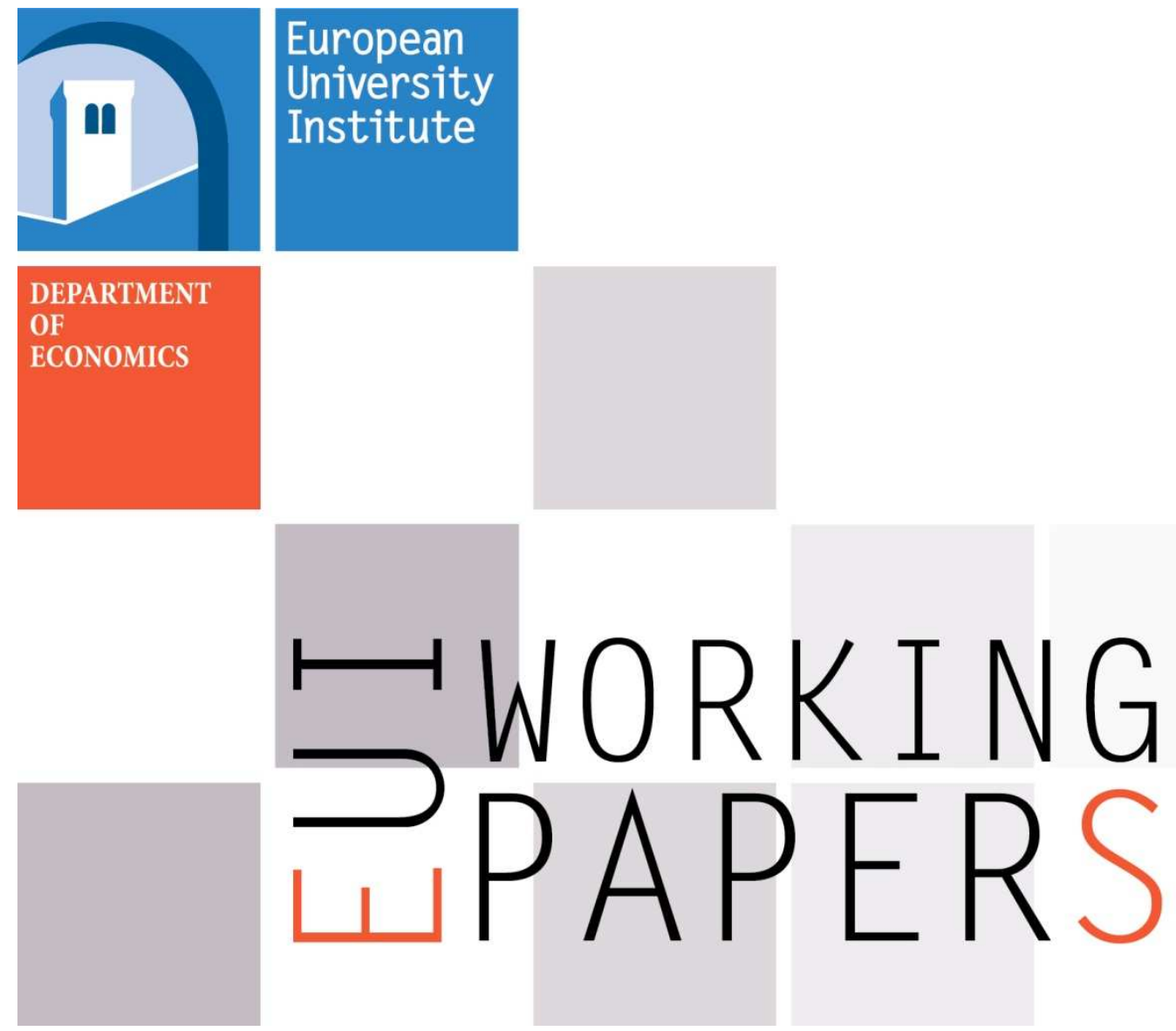

ECO 2013/08

Department of Economics

SECOND-DEGREE MORAL HAZARD IN A REAL-WORLD CREDENCE GOODS MARKET

Loukas Balafoutas, Rudolf Kerschbamer and Matthias Sutter 

European University Institute

Department of Economics

Second-Degree Moral Hazard in a

Real-World Credence Goods Market

Loukas Balafoutas, Rudolf Kerschbamer and Matthias Sutter

EUI Working Paper ECO 2013/08 
This text may be downloaded for personal research purposes only. Any additional reproduction for other purposes, whether in hard copy or electronically, requires the consent of the author(s), editor(s). If cited or quoted, reference should be made to the full name of the author(s), editor(s), the title, the working paper or other series, the year, and the publisher.

ISSN 1725-6704

(C) Loukas Balafoutas, Rudolf Kerschbamer and Matthias Sutter, 2013

Printed in Italy

European University Institute

Badia Fiesolana

I - 50014 San Domenico di Fiesole (FI)

Italy

www.eui.eu

cadmus.eui.eu 


\title{
Second-Degree Moral Hazard in a Real-World Credence Goods Market*
}

\author{
Loukas Balafoutas \\ University of Innsbruck \\ Rudolf Kerschbamer \\ University of Innsbruck \\ Matthias Sutter ${ }^{\#}$ \\ European University Institute Florence, IZA Bonn, and CESifo Munich
}

\begin{abstract}
Empirical literature on moral hazard focuses exclusively on the direct impact of asymmetric information on market outcomes, thus ignoring possible repercussions. We present a field experiment in which we consider a phenomenon that we call second-degree moral hazard the tendency of the supply side in a market to react to anticipated moral hazard on the demand side by increasing the extent or the price of the service. In the market for taxi rides, our moral hazard manipulation consists of some passengers explicitly stating that their expenses will be reimbursed by their employer. This has an economically important and statistically significant positive effect on the likelihood of overcharging, with passengers in that treatment being about $13 \%$ more likely to pay higher-than-justified prices for a given ride. This indicates that second-degree moral hazard may have a substantial impact on service provision in a credence goods market.
\end{abstract}

JEL-Code: C93, D82

Keywords: Natural field experiment, credence goods, asymmetric information, moral hazard, overcharging, overtreatment, taxi

This version: 16 October 2013

\footnotetext{
* We thank Marco Castillo, Nikos Nikiforakis, Ragan Petrie, Achim Zeileis, as well as audiences at the universities of Innsbruck and Cologne for very helpful comments. Special thanks are due to Konstantinos Konstantakis, Vasileios Selamis, Christina Tseligka and Amaryllis Zeppou for assisting in the experiment. Financial support from the Austrian Science Fund (FWF grant P20796) is gratefully acknowledged.

\# Corresponding author. European University Institute Florence, Department of Economics, Via della Piazzuola 43, I-50133 Florence, Italy. matthias.sutter@eui.eu
} 


\section{Introduction}

Studying the crucial role of asymmetric information on market outcomes has a long tradition in economic theory, in particular in models that demonstrate market failure when asymmetrically informed agents interact with each other. The phenomenon known as moral hazard (Pauly, 1974; Holmstrom, 1979) generally states that agents who do not bear full responsibility for the costs or risks associated with their actions will tend to exercise less effort to reduce these costs. When applied to markets for insurance, the moral hazard hypothesis states that agents with a more comprehensive insurance coverage have less incentive to avoid exposure to risk, meaning that insured events will more often realize with fully insured agents than among those with imperfect or no coverage. A number of empirical studies have tested for the presence of moral hazard in markets plagued by asymmetric information, with generally mixed results. For instance, Chiappori et al. (1998) and Einav et al. (2013) find some evidence of moral hazard in the demand for medical services and for health insurance, while Chiappori and Salanié (2000) and Doran et al. (2005) reject the moral hazard hypothesis in the markets for prescription medicine and for automobile insurance, respectively.

In an organizational context, moral hazard can manifest itself in the relation between owners and managers of a firm in the case of misaligned incentives and unobservable employee effort, for instance (Grossman and Hart, 1983; Mookherjee, 1984). ${ }^{1}$ One example of employee effort that is subject to moral hazard is the investment in cost-reduction regarding expense accounts, travel costs, and company cars or, more generally, any "hidden" effort geared towards cost minimization. The presence of moral hazard in this particular context is an important consideration among practitioners in the field. ${ }^{2}$

The existing empirical studies on moral hazard focus exclusively on the direct impact of asymmetric information on market outcomes, thereby ignoring possible repercussion effects. As an illustration consider the market for health care services and assume that the consumer of the service - in this case, a patient - is fully insured and interacts with a seller of the service - in this case, a physician. Moral hazard implies that the patient may have incentives to demand more of the service than required (by asking for more numerous or more extensive tests or treatments), since she will not bear its costs. However, the behavior of the

\footnotetext{
${ }^{1}$ See also Itoh (2004) and Bartling and von Siemens (2010) for models that incorporate social comparisons into the principal-agent setting.

${ }^{2}$ See, for example, a CNN report on expense account fraud and the extent to which business travelers tend to inflate their expenses (including taxi receipts): http://edition.cnn.com/2011/12/05/travel/expense-accountbusiness-travel/index.html.
} 
physician may also be affected by the extent of the coverage: if the physician expects that the patient is not concerned about minimizing costs, he may be more inclined to suggest or prescribe more expensive treatments. Notice that the two stories - which we will call firstdegree moral hazard and second-degree moral hazard - are observationally equivalent in terms of final outcomes, in the sense that more extensive insurance coverage leads to higher expenditure, but the mechanisms are different. While first-degree moral hazard operates through the demand side, second-degree moral hazard increases expenditure through supplierinduced demand - the artificial increase in demand induced by the actions of the seller.

A similar second-degree moral hazard story also applies to the above example on the lack of cost-minimizing incentives by firm employees. Consider the case of an employee who must travel for work purposes and is responsible for booking the tickets himself. Since he will be fully reimbursed for his expenses, his incentives for finding and buying the lowest fare are weak (first-degree moral hazard). Moreover, if he visits a travel agent and informs her of the purpose of travel, the agent may deliberately suggest only expensive travel options or charge a higher than justified commission, anticipating that the employee will not put any effort into monitoring or protesting the agent's actions (second-degree moral hazard).

In this paper we present the findings from a field experiment that studies the impact of full reimbursement (or coverage) of expenses on ex post realized expenditures induced by the actions of the service provider - and not of the consumer. To our knowledge this is the first study to examine the possibility that second-degree moral hazard may be partly responsible for the positive correlation between coverage and realized expenditure. A further contribution of our paper is that, to the best of our knowledge, it is the first to use a controlled field experiment to study (second-degree) moral hazard and its impact on market outcomes (for a general discussion on field experiments and the advantages of this methodology, see List, 2006, and List and Reiley, 2008).

We have conducted our study in the market for taxi (cab) rides. In the case of taxi rides in an unknown city, the service traded on the market is a credence good (Darbi and Karni, 1973), meaning that an expert seller possesses superior information about the needs of the consumer. ${ }^{3}$ In particular, the driver knows the correct route to a destination while the consumer does not. This property of credence goods opens the door to different types of fraud: overtreatment occurs when the consumer receives more extensive treatment than what is necessary to meet her needs (with taxi rides, this amounts to a detour); in the opposite case

\footnotetext{
${ }^{3}$ For some theoretical and experimental work on the properties of credence goods markets see Dulleck and Kerschbamer (2006), and Dulleck et al. (2011). Related work on the effects of informational asymmetries in experience goods markets is by Huck et al. $(2007,2012)$.
} 
of undertreatment, the service provided is not enough to satisfy the consumer (i.e., she does not reach her destination); finally, in credence goods markets where the consumer is unable to observe the quality he has received, there might also be an overcharging incentive, meaning that the price charged by the seller is too high given the service that has been provided.

In the context of credence goods markets such as taxi rides or medical and repair services, second-degree moral hazard seems particularly relevant because the informational asymmetries present in such markets facilitate supplier-induced demand, or even fraud (see Sülzle and Wambach, 2005 for a theoretical model). In a recent field experiment, Balafoutas et al. (2013) have examined the role of information in the market for taxi rides and established that fraud by taxi drivers is very systematic in the sense that it increases with the extent of the informational asymmetry between the seller (driver) and the consumer (passenger). This paper uses a methodology very similar to that in Balafoutas et al. (2013), but applies it to the research questions discussed above. ${ }^{4,5}$

Specifically, in our study a team of research assistants took 256 undercover taxi rides in the capital city of Greece, Athens. The assistants, acting as passengers on eleven different routes throughout the city, always revealed to the driver that they were unfamiliar with the city, thus giving the taxi ride characteristics of a typical credence good. Our main experimental variation consisted solely of a short phrase in one of the two treatments, in which the passengers indicated that they needed a receipt in order to have their expenses reimbursed by their employer. We call this the "moral hazard treatment", in the sense that the passenger conveyed the impression of not being personally incurring the costs of the fare and was therefore arguably perceived by the driver as less likely to notice, or report, fraudulent behavior on his side.

We find that our moral hazard manipulation has an economically pronounced and statistically significant positive effect on the likelihood of overcharging, with passengers in that treatment being about $13 \%$ more likely to pay higher-than-justified prices for a given ride. This also leads to higher consumer expenditures in this treatment, on average. At the same time, the rate of overtreatment (by taking detours) does not differ across treatments,

\footnotetext{
${ }^{4}$ There is an interesting literature on the labor supply of (New York City) taxi drivers (see, e.g., Camerer et al., 1997; Farber, 2005, 2008; Crawford and Meng, 2011). However, this literature remains silent on the question of whether and to which extent taxi drivers exploit their informational advantage over customers in the provision of this credence good. Hence, we are not going into the details of these studies.

${ }^{5}$ Schneider (2010) and Jackson and Schneider (2011) use data from New York City taxi drivers in order to estimate the extent and determinants of moral hazard in a different dimension, namely in the relationship between owners and lessees of vehicles. As we explain in section 2.2, this aspect is not relevant in the environment of our study.
} 
something which - as we will argue - is consistent with our hypothesis regarding the way that moral hazard impacts behavior in this kind of market.

Before we proceed to describe in detail the experiment and its findings, we would like to stress once more that this paper is not a test of (first-degree) moral hazard according to its textbook definition (a privately informed party takes a hidden action that increases her risk exposure because she knows that she will not bear the costs of the risk). As a matter of fact, first-degree or direct moral hazard (on the consumer side) is ruled out in this experiment since the behavior of the passengers is exogenously controlled by the experimenters and kept constant across treatments. Our research question is how the perception that moral hazard exists in the relationship between the consumer and the reimbursing employer affects the seller of the service. We have called this mechanism second-degree moral hazard, and whenever the term moral hazard shows up in the following it refers to this kind of mechanism.

\section{Experimental Design and Implementation}

\subsection{Experimental Methods}

The field experiment was run by means of taking undercover taxi rides. Our four research assistants presented themselves as customers and documented the driving and charging decisions of taxi drivers (who were unaware that their behavior was being studied). Each observation consisted of an assistant entering a taxi and requesting to be taken to a particular destination, following a fixed script: "I would like to get to [name of destination]. Do you know where it is? I am not from Athens." This is the script used in Balafoutas et al. (2013) for the role of non-local native passengers - i.e., for passengers who speak the native language but clearly indicate to the driver that they are not familiar with the city. Arguably, this means that the taxi ride is considered a credence good by the driver, in the sense that the driver expects to have an informational advantage that he or she may try to exploit. ${ }^{6}$

We implemented two treatments. In the Control Treatment (henceforth CTR), a few seconds after the ride had begun the passenger added the following question to the driver: "Can I get a receipt at the end of the ride?" In the Moral Hazard Treatment (henceforth $\mathrm{MOH})$ the same question was supplemented by a short phrase explaining that the passenger would have his or her expenses reimbursed: "Can I get a receipt at the end of the ride? I need

\footnotetext{
${ }^{6}$ This is in sharp contrast to the field study by Castillo et al. (2013) on gender differences in bargaining outcomes in the market for taxi-cab rides in Lima, Peru. In that study the undercover customers are locals who know the shortest route to their destination. This implies that the core credence good problem in the market for taxi rides (overtreatment in the form of taking circuitous routes) is absent. Also, taxis in Lima do not have posted prices and meters - prices are rather set by face-to-face negotiations. This implies that overcharging is not an issue in the Lima study either.
} 
it in order to have my expenses reimbursed by my employer." The two treatments were exactly identical except for this brief additional phrase, allowing us to identify the potential effects of this revealed information. Our hypothesis is that fraudulent behavior will be more prevalent or more pronounced in the moral hazard treatment, since - as explained in the introduction - drivers may infer that passengers in this treatment have weak incentives to control, or to report, overtreatment or overcharging. ${ }^{7}$ Even though our hypothesis does not differentiate between the two fraud dimensions (overtreatment and overcharging) and predicts that both will be more widespread or more pronounced in treatment $\mathrm{MOH}$, there are good reasons to expect that drivers will respond more intensively in the overcharging dimension. We will outline these reasons in section 3.4.

In addition to this treatment manipulation, we investigated gender effects in service provision and the potential interaction of gender and moral hazard by recruiting two male and two female research assistants. Even though we had no formal prior hypothesis regarding the role of gender in the context of this experiment, intuition might lead one to expect that women fall victim to fraud more often than men, for instance, because they are perceived as less likely to engage in confrontation with the driver. Table 1 summarizes our design (including the number of collected observations).

\section{Table 1 about here}

Rides were always taken in quadruples in the sense that all four assistants took taxis from the same origin to the same destination, in intervals of one to two minutes between each other. This design feature was implemented in order to control for factors unrelated to the treatment manipulation but possibly related to the optimal route and to the price of the ride, such as traffic and weather conditions, unforeseen or time-specific events such as closed roads, etc. Within each quadruple, the order of entering the taxi was random, and two passengers (one female and one male) enacted the control treatment, while the other two enacted the moral hazard treatment. As a result, all four cells of the experimental design (Table 1) are represented in each quadruple.

\subsection{The Market Environment}

The market for taxi rides is regulated nationwide in Greece, both in market entry and the tariff system. A government authority issues taxi licenses as perpetuities for their holders.

\footnotetext{
${ }^{7}$ Note that reporting fraud to transportation authorities can, in principle, lead to the loss of a taxi license.
} 
Currently, approximately 14,000 taxi licenses are valid in Athens, implying a ratio of roughly 350 taxis per 100,000 inhabitants. This is a considerably larger supply than, for instance, in London with 280 taxis, Berlin with 210 taxis, New York City with 160 taxis (yellow cabs only), or the whole U.S. with around 110 taxis per 100,000 inhabitants. ${ }^{8}$

The tariff system is regulated such that there is a fixed fee of $€ 1.19$ and a variable part. The variable part is either distance-dependent - in this case the tariff is $€ 0.68$ per kilometer during daytime (i.e., from 5 a.m. until midnight) and $€ 1.19$ per kilometer during nighttime or duration-dependent - then it yields $€ 0.1808$ per minute both during daytime and during nighttime. The algorithm for charging is standardized nationwide in all taximeters and switches automatically to the counting method (distance-dependent vs. duration-dependent) that is more profitable for the driver. Given the large supply of taxis in Athens, drivers typically have to queue for passengers for long periods of time. This implies that it is generally by far more profitable for a taxi driver to take a passenger on a detour - thus providing overtreatment - than to choose the shortest and quickest route in the hope to accumulate many fixed fees. Moreover, abstracting from possible punishment, there are clear incentives for overcharging, since it increases the driver's revenue without affecting the cost of service. Note that the marginal incentives of taxi drivers to engage in fraud of any type are practically identical both for owners of the taxi and those drivers who lease the vehicle, because leasing a taxi comes at a fixed cost (of roughly €35 per shift; see www.satataxi.gr). Therefore, taxi drivers are always residual claimants, meaning that the possible profits from fraud are reaped by themselves.

Since January 2013, every consumer in Greece has the right to refuse payment for a transaction of a good or service if a legal receipt has not been issued. Accordingly, every taxi is equipped with a small cash register, which is connected to the taximeter and automatically produces a receipt at the end of each ride. This implies that asking for a receipt should have no effect per se, and in fact our assistants only did so to have an anchor for adding the phrase explaining that they are having their expenses reimbursed (in the moral hazard treatment) and to keep the script identical across treatments as much as possible.

\subsection{Dataset}

The experiment was conducted during nine days in March 2013, covering each day of the week at least once. All rides were taken between 8 am and midnight on eleven different routes

\footnotetext{
8 Source: Own calculations, based on numbers from The New York City Taxicab Fact Book (2006), "Transportation for London" (http://www.tfl.gov.uk/businessandpartners/taxisandprivatehire/1380.aspx), "Taxi Innung Berlin" (http://www.taxiinnung.org/Taxi-Bestellen.24.0.html), and Schaller (2005).
} 
throughout the city of Athens, randomizing among routes during the day (meaning that data on each route were collected during several days, and that several routes were driven each day, in random order). ${ }^{9}$ We collected a total of 256 observations, organized in 64 quadruples of (almost) simultaneous rides. The mean length of a ride was 15.78 kilometers and the mean duration was 23.7 minutes, thus amounting to a total of about 4,040 kilometers and 101 hours of driving.

For each observation our assistants collected the following data: date and time at the start of the ride; route; duration; distance driven; total price (fare) paid; gender and approximate age of the driver; vehicle manufacturer; weather and traffic conditions.

The exact distance driven was measured with a portable GPS satellite logger (see Picture A.1 in the Appendix) that records the chosen route and the taxi's exact position and speed at each point in time. With these data, we could quantify overtreatment in the form of detours and determine the correct fare for the driven distance. From that we created an overcharging indicator, which is one if a driver asked for more than justified by the driven distance and zero otherwise. In order to classify the source of overcharging, we resorted to the detailed information collected by our assistants, describing whether the driver artificially increased the fare for a given ride (e.g., by demanding unjustified extras or applying an incorrect tariff). We also computed the overcharging amount, defined as the difference between the total price and the price that should have been paid for the actually driven distance - or, in other words, the amount by which the customer was cheated (on top of potential overtreatment through detours). We classify an observation as a case of overcharging if the amount of this mark-up is at least $5 \%$ of the total price paid, noting that all our results are robust to extending the definition of overcharging to include lower amounts. ${ }^{10}$

\section{Results}

\subsection{Overtreatment}

In order to quantify overtreatment we have constructed an overtreatment index by dividing the distance in each observation by the minimum distance recorded in that particular quadruple. The index thus controls for all unobserved characteristics related to driving conditions (such as traffic). A potential drawback of the index is that cases where overtreatment takes place in all four rides within a quadruple would lead to an underestimation of overtreatment. We

\footnotetext{
${ }^{9}$ For a list of all routes and brief description of the points of origin and destination, please refer to Tables A.1 and A. 2 in the appendix.

${ }^{10}$ Note that the experimenters always paid exactly the price the taxi driver requested. They never gave any tip, and taxi drivers never asked for any.
} 
therefore check the robustness of our findings in this respect by also presenting an alternative overtreatment index, which normalizes the distance in each observation by the minimum possible distance for the route. To identify the minimum possible distance we used data from google maps and also drove all the routes ourselves, following the directions of the navigation system "TomTom".

The values of the two overtreatment indices by treatment and gender are shown in Table 2. No substantial differences are observed across treatments or across gender, and this impression is confirmed by statistical tests. In particular, we test for treatment differences by taking the mean value of the index for the two passengers in CTR in a given quadruple and comparing it with the mean value of the two passengers in $\mathrm{MOH}$ in the same quadruple, in order to account for the fact that observations are not independent within each quadruple due to the way the overtreatment index is constructed. This leads to a total of 64 observations on paired samples and the null hypothesis of no significant treatment difference is not rejected by Wilcoxon signed-ranks tests ( $p=0.70$ for both overtreatment indices). ${ }^{11}$ Moreover, men and women are also not taken on rides of different length, on average. Hence, we are led to conclude that our treatment manipulation has had no detectable effect on the first dimension of fraud, overtreatment.

\section{Table 2 about here}

We also note that we observe no treatment differences with respect to the mean duration of a ride, which could in principle be shorter if drivers made efforts to take shortcuts, or longer if they chose routes on which they expected to encounter heavy traffic. There is no evidence of such effects in our data: the mean duration index (defined as the duration of a ride divided by the minimum duration in that quadruple) is 1.14 both in $\mathrm{MOH}$ and in CTR ( $\mathrm{p}=$ 0.97, Wilcoxon signed-ranks test).

\subsection{Overcharging and Total Fare}

The values in Table 3 report the frequency with which drivers overcharged their customers. In total, some form of overcharging was observed in 74 of 256 rides, or in $28.9 \%$ of all cases. ${ }^{12}$ In the large majority of these cases (53 out of 74 , or $71.6 \%$ ) bogus surcharges were applied,

\footnotetext{
${ }_{12}^{11}$ All the p-values reported in the paper refer to two-sided tests.

${ }^{12}$ In Balafoutas et al. (2013), the overall overcharging rate is $11.2 \%$, and therewith considerably lower. However, the only clean comparison (with identical treatment conditions) is between male non-local natives in Balafoutas et al. (2013) - with 7.8\% overcharging rate - and male experimenters in the CTR-condition here with $14.1 \%$ overcharging rate. This difference is not significantly different according to a $\chi^{2}$-test $(\mathrm{p}>0.1)$.
} 
namely higher-than-justified extras from and to the airport, the port, the railway station and the bus station. The second most frequent source of overcharging (eleven cases) were manipulated taximeters or the use of the night tariff during daytime, while rounding-up (not tipping!) of the price (by more than 5\%) accounted for the remaining ten cases of overcharging.

\section{Table 3 about here}

The comparison between the two treatments reveals that overcharging was much more frequent in the moral hazard treatment (35.2\% vs. $22.7 \% ; p=0.038$, Fisher's exact test). We view this as the single most important finding of our study, because it points towards a statistically significant and economically important causal effect of second-degree moral hazard on market outcomes in the credence goods setting under consideration.

Disaggregating by gender gives a more nuanced impression of this treatment effect. As it turns out, in the control treatment women face overcharging more frequently than men ( $32 \%$ vs. $25.8 \% ; p=0.034$, Fisher's exact test), but at the same time the charging behavior towards them is much less responsive to our moral hazard manipulation. While the rate of overcharging increases by less than 2 percentage points for women in treatment $\mathrm{MOH}$ compared to CTR, the difference is much more pronounced and statistically significant for male passengers $(37.5 \%$ vs. $14 \%$; $=0.004$, Fisher's exact test), so that in the presence of moral hazard the rates of overcharging are very similar across gender. We are thus led to conclude that the effect of the moral hazard manipulation on overcharging is mainly driven by the subgroup of male passengers.

Although overcharging is more frequent in treatment $\mathrm{MOH}$, conditional on overcharging having taken place the amount by which drivers artificially increased the payable fare is lower in this treatment than in the control (€3.53 vs. €4.81). The mean overcharging amount by treatment and gender is also shown in Table 3. This finding is somewhat surprising. It must be noted, however, that it is not significant, as the following section with econometric estimations will reveal. The amount of overcharging does not differ significantly by gender.

Given the substantially higher overcharging frequency in the moral hazard treatment and the absence of a significant treatment difference with respect to overtreatment, it is natural to expect that second-degree moral hazard will have a positive overall impact on the total price paid by passengers, thereby reducing consumer surplus. Indeed, this turns out to be 
the case. Table 4 reports the price index by treatment and gender, defined in a way analogous to the overtreatment index (the price paid divided by the minimum price in that particular quadruple). The mean value of the index is higher in $\mathrm{MOH}$ than in CRT, and the difference is weakly significant $(\mathrm{p}=0.067$; Wilcoxon signed-rank test). Graphically this impression is confirmed in Figure 1, which shows that the cumulative distribution function of the price index in treatment $\mathrm{MOH}$ first-order stochastically dominates that in treatment CTR. This information is useful in its own right since it implies that consumer expenditures will be higher in the presence of moral hazard, ceteris paribus (even if it does not convey information about the source of the price increase).

\section{Table 4 and Figure 1 about here}

\subsection{Econometric Analysis}

Econometric estimations confirm all of the above insights. Given the absence of a treatment difference in the overtreatment dimension of fraud, we restrict our attention to overcharging and the total price paid. Table 5 reports the results from three regression specifications. In column (1) the dependent variable is the overcharging indicator and the model used is the Probit; in (2) we use a truncated regression to estimate the amount of overcharging, conditional on a positive value of the overcharging indicator. Hence, the first two columns of Table 5 correspond to the two stages that are implicit in the driver's charging decision, and which can be attributed to the same latent variable determining the strength of the driver's propensity towards fraud in this dimension. First the driver decides whether to overcharge a passenger, and then, if so, by how much. Finally, in the third specification we use a Tobit model with the price index as the dependent variable (left-censored at 1). In all three models standard errors are clustered by quadruple, in order to account for the interdependencies among the four simultaneous rides. We also include route fixed effects, since some routes (in particular the relatively longer ones) are more susceptible to fraudulent behavior by drivers. ${ }^{13}$

Table 5 about here

\footnotetext{
${ }^{13}$ All of the results that are presented in this section are robust to alternative specifications, such as experimenter fixed effects, time fixed effects, or the inclusion of further explanatory variables (driver's age, vehicle type, weather conditions etc.). These additional explanatory variables are always insignificant and lead to a worsening of the Akaike and Bayesian Information Criteria.
} 
The Probit regression on overcharging shows that its likelihood increases by $29 \%$ in the treatment with moral hazard. At the same time, the positive and highly significant coefficient on female passengers indicates that women are $22.9 \%$ more likely than men to face overcharging in the control treatment. However, as we have already seen, behavior towards female passengers is far less responsive to our treatment manipulation - something that is captured by the large negative coefficient on the interaction term. In the truncated regression on the overcharging amount the moral hazard treatment dummy has a negative coefficient, consistent with the means reported in Table 3; nevertheless, the coefficient is statistically indistinguishable from zero. This suggests that moral hazard affects the decision on whether to overcharge a customer, but - conditional on overcharging - the extent of fraud remains largely unaffected.

In line with the qualitative differences observed in Table 4, the moral hazard treatment leads to a higher total price for customers. The difference amounts to $6.7 \%$ and is weakly significant $(\mathrm{p}=0.066)$. One must keep in mind that the effect of $\mathrm{MOH}$ on the price index is the sum of three partial effects, namely the strong positive and highly significant impact on the likelihood of overcharging, the negative but insignificant impact on its amount, and the negligible impact on the distance driven (overtreatment). As it turns out, in the end the service is provided for a higher price in the presence of moral hazard.

\section{Discussion}

\subsection{Overtreatment versus Overcharging}

We have documented the presence of strong treatment differences with respect to overcharging behavior and in particular the frequency with which the phenomenon occurs. On the other hand, the value of the overtreatment index is almost identical across treatments. Why is it that drivers only change their behavior in the former fraud dimension, but not in the latter? One plausible and straightforward explanation is that overcharging is more lucrative and increases the driver's income without any additional costs such as fuel costs, depreciation etc. Therefore, provided a driver believes that his (or her) passenger will not complain about a price increase due to fraud in treatment $\mathrm{MOH}$, he (or she) should resort to overcharging in order to achieve this price increase.

A further explanation for the observed data pattern relies on the opportunity costs of time. In particular, it is reasonable for a driver to expect that a passenger in the moral hazard treatment - but not in the control treatment - does not mind paying a higher price, but that the passenger does mind being taken on a detour because he or she bears a cost in the form of the 
longer duration of the ride. Then, a driver who wants to increase income and at the same time reduce the likelihood of being confronted by a passenger should overcharge the passenger, but not overtreat him.

\subsection{Alternative Explanations for the Observed Treatment Differences}

Our main research hypothesis and the experimental design are based on the premise that service provision in credence goods markets is affected by second-degree moral hazard as we have defined it in the introduction. Hence, our explanation for the higher prices and overcharging frequencies in treatment $\mathrm{MOH}$ is that passengers in that treatment are perceived as less likely to exert control on the taxi driver, because they have revealed that their expenses are reimbursed by their employer. This means that fraudulent behavior is more likely to go undetected or unreported. Anticipating this, expert sellers exercise fraud more frequently. Nevertheless, we must acknowledge the existence of other possible explanations, which could to some extent be driving the treatment differences observed in the data.

\section{The Role of Adverse Selection}

Adverse selection (Akerlof, 1970; Rothschild and Stiglitz, 1976) is another much-studied consequence of asymmetric information. It implies that, when agents have private information about their risk types, high-risk agents are more inclined to buyextensive insurance coverage than low-risk ones. A direct implication of this tendency is a positive correlation between the extent of insurance coverage and the ex post realizations of risk in a given market. The empirical literature on asymmetric information and its impact on market outcomes has difficulties to distinguish between adverse selection and moral hazard, since both predict a positive correlation between coverage and ex post realizations of risk, albeit through very distinct mechanisms. ${ }^{14}$ Adverse selection implies that high-risk agents ex ante self-select into contracts with more extensive coverage, while moral hazard means that agents may increase their risk ex post because they possess more extensive coverage. Our experimental methodology rules out adverse selection because agents (passengers) do not choose between the two treatments, but are randomly assigned to one of them. This allows us to sidestep the problem of disentangling moral hazard from adverse selection, which we view as a further advantage of our study.

\footnotetext{
${ }^{14}$ For instance, Chiappori and Salanié (2000, p. 60) acknowledge that "the general problem of distinguishing between adverse selection and moral hazard from insurance data is left for future research [.]" A recent attempt to disentangle the two phenomena using automobile insurance data from France is found in Dionne et al. (2013).
} 
Firms versus Individuals: Distributional Preferences

It could be argued that drivers are more willing to overcharge passengers who are having their expenses reimbursed by a firm not because of the role of second-degree moral hazard, but due to the fact that firms are considered as wealthier than individuals. If this is the case and if drivers are motivated by convex distributional preferences then they might be inclined to charge more when a firm is liable for the payment. This argument could be substantiated by referring to the experimental evidence indicating that distributional preferences are behaviorally relevant in many important market and non-market transactions (see Cooper and Kagel, 2012, for a recent survey), and that subjects in the lab indeed decide in conformity with convex distributional preferences (see Fehr and Schmidt, 1999; Bolton and Ockenfels, 2000; or Charness and Rabin, 2002, for instance). While this is a plausible argument, we note that in Balafoutas et al. (2013) we have explicitly tested for the impact of distributional preferences on service provision in this particular (taxi) market and have failed to find evidence to support such an impact on overtreatment or overcharging decisions.

\section{Firms versus Individuals: Morality of Fraud and Social Distance}

Another reason why drivers might be more inclined to overcharge clients who are being reimbursed by their employer is that they feel more comfortable when the victim of fraud is eventually an anonymous entity, as opposed to a specific individual. This could be based either on moral considerations that make a driver more reluctant to steal from an individual than from a legal entity, or on social distance that makes the driver more reluctant to steal from someone who he (or she) directly interacts with than from an anonymous third party. ${ }^{15}$ While we cannot entirely rule out such explanations for our treatment differences, we note that they cannot explain why we observe treatment differences only in overcharging, and not in overtreatment decisions by drivers. On the contrary, we have argued in section 4.1 that an explanation based on moral hazard on the consumer's side is consistent with the specific pattern we see in the data. In any case, even if those alternative explanations for the treatment differences matter, the implications of our findings would remain the same: Market participants who are perceived as having their expenses covered by an anonymous legal person will be more likely to face overcharging than those who are paying for the service themselves, resulting in more frequent fraud and higher overall expenditures in the market.

\footnotetext{
${ }^{15}$ On the effects of social distance on behavior, see, for instance, Charness, Haruvy and Sonsino (2007) or Goette, Huffman and Meier (2012).
} 


\section{Conclusion}

We have presented a field experiment on fraud in a market for a credence good - taxi rides in an unknown city. To the best of our knowledge, ours is the first controlled field experiment to study moral hazard and how it affects market outcomes. Our setting has allowed us to examine the impact of what we have called second-degree moral hazard on the provision of this good. By doing so we have studied the supply side, rather than the consumer side, and how it reacts to moral hazard on the side of the consumer. We consider the latter an important extension of the existing literature because the welfare consequences of this indirect effect of moral hazard might even exceed those of the direct effect. In the context of credence goods markets, this mechanism is particularly relevant because the informational asymmetries present in such markets facilitate supplier-induced demand, or even fraud.

In our experiment we find that our moral hazard manipulation has an economically important and statistically significant positive effect on the likelihood of overcharging, with passengers in that treatment being about $13 \%$ more likely to pay higher-than-justified prices for a given ride. This indicates that second-degree moral hazard may have a substantial impact on service provision in a credence goods market. Interestingly, but in line with our hypothesis, we find no treatment effect on overtreatment, which is measured as the amount of detours taken by taxi drivers. Indeed, the distance seems to be unaffected by moral hazard, while the likelihood of cheating on the bill increases substantially.

Our findings are consistent with anecdotal evidence that perceived moral hazard leads to higher bills, and thus higher costs in the health care system. For instance, the health care system in Germany is allegedly prone to physicians inflating patients' bills through adding services on the bill which have not been provided. ${ }^{16}$ Given that patients do not need to worry about the bill when they are insured because insurance companies reimburse the physicians' bills, this is perhaps not surprising. Moreover, as we have argued in the introduction, full reimbursement of expenses may lead to inflated bills for firms due to their employees having weak incentives to minimize costs in a number of credence goods situations ranging from a simple taxi ride - like in our design - to high repair costs for company cars or computers. In all of these cases, we have argued that part of the problem can be found in the employee's weak incentive to exert control on the behavior of an expert seller, which may induce the

\footnotetext{
${ }^{16}$ See, for example, a report in the German weekly magazine "Der Spiegel" from 23 December 2012 in which the yearly damage to insurers from faked and inflated bills is estimated to account for 6 to 24 billion Euro. http://www.spiegel.de/wirtschaft/krankenkassen-detektive-jagen-betruegerische-aerzte-mit-spezialsoftware-a873059.html
} 
latter to increase the extent or the price of the service. Yet, so far there has been no study that systematically - and under controlled conditions - has shown how second-degree moral hazard influences the supply side in a credence goods market. Our paper has taken a first step in doing so. 


\section{References}

Akerlof, George. 1970. “The Market for 'Lemons': Quality Uncertainty and the Market Mechanism." Quarterly Journal of Economics 84 (3): 488-500.

Balafoutas, Loukas, Beck, Adrian, Kerschbamer, Rudolf, and Sutter, Matthias. 2013. "What Drives Taxi Drivers? A Field Experiment on Fraud in a Market for Credence Goods." Review of Economic Studies 80(3): 876-91.

Bartling, Björn, and von Siemens, Ferdinard. 2010. "The Intensity of Incentives in Firms and Markets: Moral Hazard with Envious Agents." Labor Economics 17: 598-607.

Bolton, Gary E., and Ockenfels, Axel. 2000. "ERC: A Theory of Equity, Reciprocity, and Competition." American Economic Review 90(1): 166-93.

Camerer, Colin, Babcock, Linda, Loewenstein, George, and Thaler, Richard. 1997. "Labor Supply of New York City Cabdrivers: One Day at a Time. Quarterly Journal of Economics 112(2): 407-41.

Castillo, Marco, Petrie, Ragan, Torero, Maximo, and Vesterlund, Lise. 2013. "Gender Differences in Bargaining Outcomes: A Field Experiment on Discrimination”. Journal of Public Economics 99: 35-48.

Charness, Gary, Haruvy, Ernan, and Sonsino, Doron. 2007. "Social Distance and Reciprocity: The Internet vs. the Laboratory." Journal of Economic Behavior and Organization 63: 88-103.

Charness, Gary, and Rabin, Matthew. 2002. "Understanding Social Preferences with Simple Tests.” Quarterly Journal of Economics 117(3): 817-69.

Chiappori, Pierre-André, and Salanié, Bernard. 2000. "Testing for Asymmetric Information in Insurance Markets.” Journal of Political Economy 108 (1): 56-78.

Chiappori, Pierre-André, Durand, Franck, and Geoffard, Pierre-Yves. 1998. "Moral Hazard and the Demand for Physician Services: First Lessons from a French Natural Experiment." European Economic Review 42: 499-511.

Cooper, David J., and Kagel, John H. 2012. "Other Regarding Preferences: A Selective Survey of Experimental Results.” In: John H. Kagel and Alvin Roth (eds.), Handbook of Experimental Economics, Vol. 2, Princeton, Princeton University Press.

Crawford, Vincent P., and Meng, Juanjuan. 2011. 'New York City Cabdrivers' Labor Supply Revisited: Reference-Dependent Preferences with Rational-Expectations Targets for Hours and Income." American Economic Review 101(5): 1912-32.

Darby, Michael R., and Karni, Edi. 1973. "Free Competition and the Optimal Amount of Fraud." Journal of Law and Economics 16(1): 67-88. 
Dionne, Georges, Michaud, Pierre-Carl, and Dahchour, Maki. 2013. "Separating Moral Hazard from Adverse Selection and Learning in Automobile Insurance: Longitudinal Evidence from France." Journal of the European Economic Association 11(4): 897-917.

Doran, Evan, Robertson, Jane, and Henry, David. 2005. "Moral Hazard and Prescription Medicine use in Australia - The Patient Perspective." Social Science \& Medicine. 60: 1437-43.

Dulleck, Uwe, and Kerschbamer, Rudolf. 2006. "On Doctors, Mechanics, and Computer Specialists: The Economics of Credence Goods." Journal of Economic Literature 44(1): $5-42$.

Dulleck, Uwe, Kerschbamer, Rudolf and Sutter, Matthias. 2011. "The Economics of Credence Goods: On the Role of Liability, Verifiability, Reputation and Competition." American Economic Review 101(2): 526-55.

Einav, Liran, Finkelstein, Amy, Ryan, Stephen, Schrimpf, Paul, and Cullen, Mark R. 2013. "Selection on Moral Hazard in Health Insurance." American Economic Review 103(1): 178-219.

Farber, Henry. 2005. "Is Tomorrow Another Day? The Labor Supply of New York City Cabdrivers." Journal of Political Economy 113(1): 46-82.

Farber, Henry. 2008. "Reference-Dependent Preferences and Labor Supply: The Case of New York City Taxi Drivers." American Economic Review 98(3): 1069-82.

Fehr, Ernst, and Schmidt, Klaus M. 1999. "A Theory of Fairness, Competition, and Cooperation." Quarterly Journal of Economics 114(3): 817-68.

Goette, Lorenz, Huffman, David, and Meier, Stephan. 2012. „The Impact of Social Ties on Group Interactions: Evidence from Minimal Groups and Randomly Assigned Real Groups." American Economic Journal: Microeconomics 4(1): 101-15.

Grossman, Sanford, and Hart, Oliver. 1983. "An Analysis of the Principal-Agent Problem." Econometrica 51(1): 7-45.

Holmström, Bengt. 1979. "Moral Hazard and Observability." Bell Journal of Economics 10(1): 74-91.

Huck, Steffen, Gabriele Lünser, and Tyran, Jean-Robert. 2007. "Pricing and Trust." UCL Working Paper.

Huck, Steffen, Gabriele Lünser, and Tyran, Jean-Robert. 2012. "Competition Fosters Trust." Games and Economic Behavior 76(1): 195-209.

Itoh, Hideshi. 2004. "Moral Hazard and Other-Regarding Preferences." Japanese Economic Review 55: 18-45. 
Jackson, C. Kirabo and Schneider, Henry. 2011. "Do Social Connections Reduce Moral Hazard? Evidence from the New York City Taxi Industry". American Economic Journal: Applied Economics 3(3): 244-67.

List, John A. 2006. "Field Experiments. A Bridge between Lab and Naturally Occurring

Data." Advances in Economic Analysis and Policy 6: Article 8.

List, John A. and Reiley, David R. 2008. "Field Experiments." in: Steven N. Durlauf and Lawrence E. Blume (eds.) The New Palgrave Dictionary of Economics. Second edition. Palgrave Macmillan.

Mookherjee, Dilip. 1984. "Optimal Incentive Schemes with Many Agents." Review of Economic Studies 51(3): 433-46.

Pauly, Mark V. 1974. "Overinsurance and Public Provision of Insurance: The Role of Moral Hazard and Adverse Selection." Quarterly Journal of Economics 88 (1): 44-62.

Rothschild, Michael and Stiglitz, Joseph E. 1976. "Equilibrium in Competitive Insurance Markets: An Essay on the Economics of Imperfect Information." Quarterly Journal of Economics 90 (4): 629-49.

Schaller, Bruce. 2005. "A Regression Model of the Number of Taxicabs in U.S. Cities." Journal of Public Transportation 8(5): 63-78.

Schneider, Henry. 2010. "Moral Hazard in Leasing Contracts: Evidence from the New York City Taxi Industry" Journal of Law and Economics 53(4): 783-805.

Sülzle, Kai, and Wambach, Achim. 2005. "Insurance in a Market for Credence Goods". Journal of Risk and Insurance 72(1): 159-76.

The New York City Taxicab Fact Book. 2006. Schaller Consulting [online]. Available from http://www.schallerconsult.com/taxi/taxifb.pdf [Accessed July 1, 2013]. 
Tables and Figures

TABLE 1.

Number of Observations by Treatment and Gender

\begin{tabular}{lccc}
\hline \hline treatment & CTR & MOH & total \\
\hline male passengers & 64 & 64 & 128 \\
female passengers & 64 & 64 & 128 \\
\hline total & 128 & 128 & 256 \\
\hline \hline
\end{tabular}


TABLE 2

Overtreatment Index (Alternative Overtreatment Index in Parentheses)

\begin{tabular}{lccc}
\hline \hline & $\mathrm{CTR}$ & $\mathrm{MOH}$ & total \\
\hline male passengers & $1.076(1.119)$ & $1.066(1.110)$ & $1.071(1.115)$ \\
female passengers & $1.060(1.104)$ & $1.076(1.121)$ & $1.068(1.113)$ \\
\hline total & $1.068(1.112)$ & $1.071(1.116)$ & $1.070(1.114)$ \\
\hline
\end{tabular}


TABLE 3

Overcharging Frequency (Mean Overcharging Amount in Parentheses, in €)

\begin{tabular}{lccc}
\hline \hline & $\mathrm{CTR}$ & $\mathrm{MOH}$ & total \\
\hline male passengers & $0.141(6.32)$ & $0.375(3.62)$ & $0.258(4.36)$ \\
female passengers & $0.313(4.14)$ & $0.328(3.42)$ & $0.320(3.77)$ \\
\hline total & $0.227(3.53)$ & $0.352(4.81)$ & $0.289(4.03)$ \\
\hline \hline
\end{tabular}


TABLE 4

Price Index

\begin{tabular}{lccc}
\hline \hline & $\mathrm{CTR}$ & $\mathrm{MOH}$ & total \\
\hline male passengers & 1.097 & 1.140 & 1.118 \\
female passengers & 1.119 & 1.145 & 1.132 \\
\hline total & 1.108 & 1.142 & 1.125 \\
\hline \hline
\end{tabular}


TABLE 5

Regressions on Overcharging and Price

\begin{tabular}{lccc}
\hline \hline & $\begin{array}{c}(1) \\
\text { Probit } \\
\text { (marginal effects) }\end{array}$ & $\begin{array}{c}(2) \\
\text { truncated } \\
\text { regression }\end{array}$ & $\begin{array}{c}\text { Tobit } \\
\text { (marginal effects) }\end{array}$ \\
\hline dependent variable & overcharging & overcharging \\
indicator & amount & price index \\
moral hazard & $0.290 * * *$ & -1.602 & $0.067 *$ \\
female & $(0.087)$ & $(1.238)$ & $(0.036)$ \\
& $0.229 * * *$ & -2.209 & 0.028 \\
female $x$ moral haz. & $(0.068)$ & $(1.685)$ & -0.040 \\
& $-0.232 * * *$ & $2.966 *$ & $(0.054)$ \\
fixed effects & $(0.071)$ & $(1.639)$ & route \\
$\mathrm{N}$ & route & route & 256 \\
\hline Standard errors in parentheses, clustered by quadruple. & 74 & \\
$* * * *$ denotes significance at the $10 \%, 1 \%$ level, respectively. &
\end{tabular}


FIGURE 1

Cumulative Distribution Function of Price Index, by Treatment

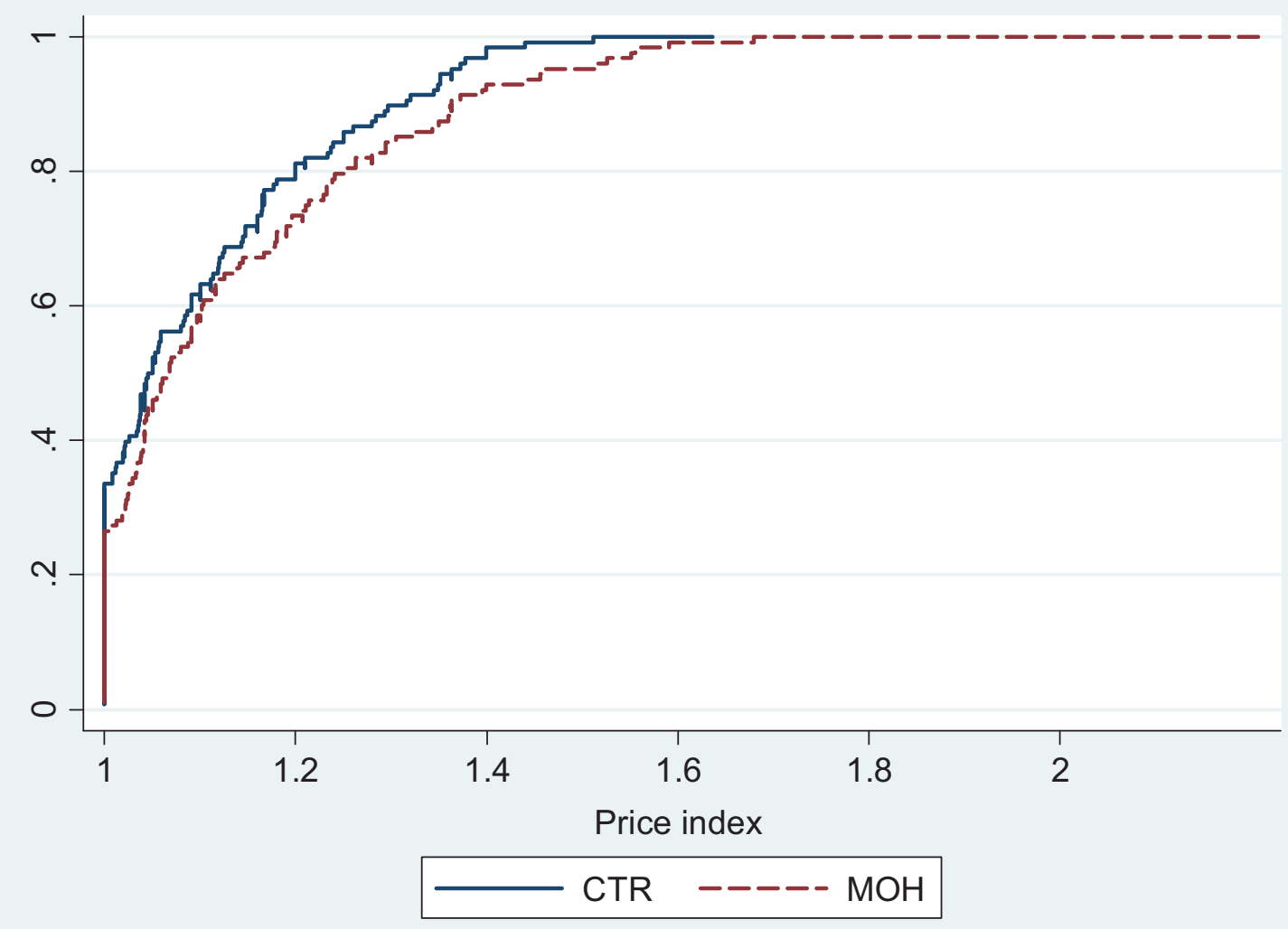




\section{Appendix}

TABLE A.1

Origins and Destinations

\begin{tabular}{ll}
\hline \hline Name & Description \\
\hline Airport & E. Venizelos International Airport \\
Glyfada & high-income suburb, southern Athens \\
Karaiskaki Square & run-down neighborhood (central) \\
Kifissia & high-income residential suburb, northern Athens \\
Port (Piraeus) & main commercial and tourist port \\
Syntagma & central square, foreigner area \\
Train Station & main train station, all intercity trains (origin only) \\
Evangelismos & central Athens \\
Bus station & main bus station, services mainly to southern and central \\
Pagrati & Greece \\
\hline \hline
\end{tabular}


TABLE A.2

Routes

\begin{tabular}{lll}
\hline \hline$\#$ & Origin & Destination \\
\hline 1 & Pagrati & Port \\
2 & Port & Karaiskaki Square \\
3 & Karaiskaki Square & Kifissia \\
4 & Kifissia & Syntagma \\
5 & Train Station & Port \\
6 & Port & Bus station \\
7 & Bus station & Port \\
8 & Evangelismos & Glyfada \\
9 & Glyfada & Evangelismos \\
10 & Airport & Glyfada \\
11 & Glyfada & Airport \\
\hline \hline
\end{tabular}




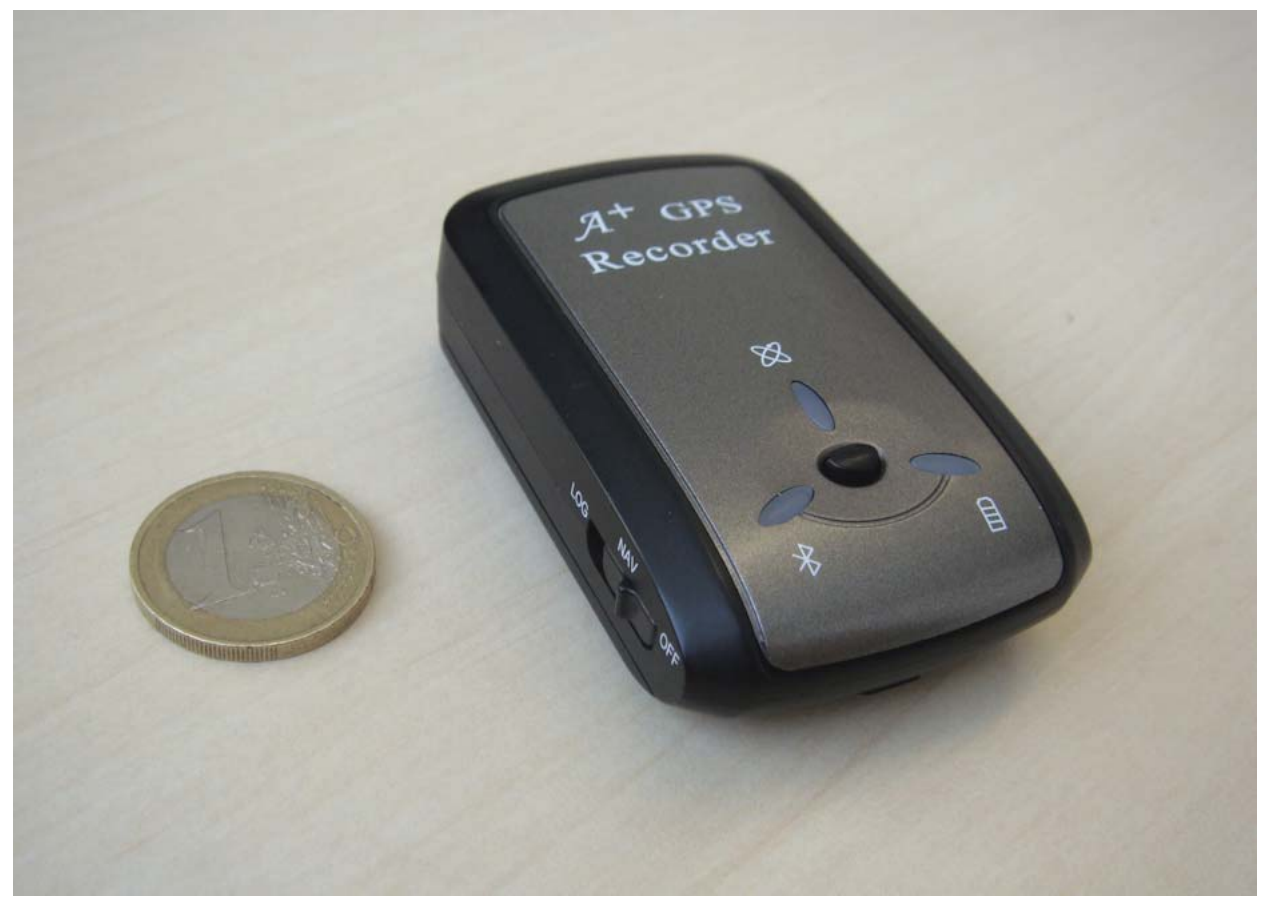

Picture A.1: GPS satellite logger used during taxi rides 


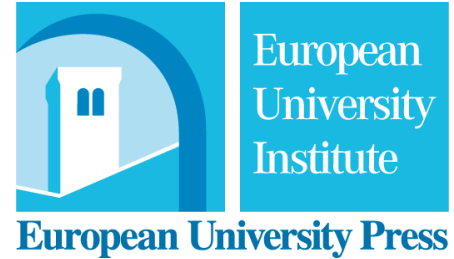

